\title{
La sacralización del miedo en el espacio urbano: el culto a la Santa Muerte
}

\author{
María Concepción Lara Mireles ${ }^{1 *}$, Jorge Arturo Mirabal Martínez ${ }^{2}$
}

\section{Resumen}

El culto a la Santa Muerte es un fenómeno sociocultural-religioso difundido ampliamente en México, particularmente en los espacios urbanos más vulnerables. En la línea de los estudios sobre cultura-comunicación urbana, se problematiza sobre las formas de socialidad en la ciudad como trama de las interacciones comunicativas, proponiendo la articulación entre espacio, significación y acción. Desde el horizonte metodológico histórico y fenomenológico, la representación social de la muerte y su "canonización" se construye en la intersubjetividad, es decir, en las interacciones comunico-culturales entre sujetos históricamente situados, en un entramado social que revela la época de crisis, violencia e incertidumbre que se atraviesa.

\section{Abstract}

The cult of Santa Muerte is a social, cultural and religious phenomenon widely known in Mexico, particularly in the most vulnerable urban spaces. This research takes place in the studies about urban culture and communication. It problematizes the ways of sociality in the city, as part of the communicative process, making the link among space, meaning and action. From the historic and phenomenological perspective, the social representation of death and its "canonization" is constructed as a result from intersubjectivity. Meaning, through the interactions of historically located subjects in their cultural communication, in a social context that reveals elements such as crisis, violence and uncertainty.

\section{Palabras Clave}

Culto a la Santa Muerte, Interacciones comunicativas, Narrativa del miedo, Espacialidad simbólica, Subjetividades emergentes

\section{Keywords}

The cult of Santa Muerte, Communicative interaction, Narrative of fear, Symbolic spaciality, Emerging subjectivities

${ }^{1}$ Doctora en Ciencias de la Comunicación Social. Universidad Autónoma de San Luis Potosí, México.

${ }^{2}$ Doctor en Comunicación Social. Universidad Autónoma de San Luis Potosí, México.

*Autor para correspondencia: laramireles@gmail.com

\section{Introducción}

La construcción social del fenómeno de la muerte es propia de cada cultura y cada época. Los pueblos construyen un andamiaje de significación en torno al hecho biológico de la muerte de los seres queridos, rodeándolo de ritualizaciones y celebraciones funerarias (Lara Mireles, 2009). La documentada obra de Philippe Ariês (2008) habla sobre las mentalidades o actitudes ante la vida y la muerte en Occidente desde el Medioevo hasta la actualidad, las cuales, señala el autor, "intentan recuperar poco a poco el camino, durante un tiempo borrado, de la muerte" (p. 267).

En algunas culturas, además de las exequias y otras costumbres funerarias, se dan concepciones religiosas por las que se deifica a la muerte, o el señorío sobre la muerte. Son productos culturales reflejo del contexto social, político, económico e ideológico de los grupos humanos que las profesan. Tal es el caso del culto a la Santa Muerte, surgido hace unos años en México y difundido particularmente en 
barrios populares y las periferias de las ciudades entre la población de escasos recursos, como vendedores ambulantes o pequeños comerciantes.

Esta devoción representa un pastiche entre reminiscencias prehispánicas y prácticas religiosas del catolicismo popular. Los lugares de culto son básicamente los espacios domésticos, como la sala de la casa o la ventana que da a la calle, pequeños altares en los corredores de los mercados, murales en bardas de terrenos baldíos y capillas improvisadas en las esquinas de las calles.

La transformación de los espacios domésticos, comerciales o de simple tránsito en territorios sagrados y culturales, esconde complejas operaciones de sentido o procesos de construcción de significación por parte de los fieles-actores sociales, ya que los creyentes otorgan a esos lugares un nuevo espesor simbólico, transformándolos en los espacios de la interacción con los otros, los cercanos que comparten la misma creencia, construyendo así una nueva narrativa urbana o compleja trama de interacciones comunicativas y conformación identitaria.

\section{Objetivo}

El propósito general de este artículo es hacer visible cómo se está configurando una narrativa social emergente o compleja trama de relaciones entre actores -seguidores de la Santa Muerte- que crean redes de interacción comunicativa incorporando prácticas rituales sincréticas, redes de construcción identitaria con formas ya tradicionales de respaldo social, para configurar un nuevo rostro colectivo: el de la emergencia de la subjetividad.

\section{Discusión teórica}

Ante la intuición primera de la complejidad que se enfrenta, se buscaron elementos que permitieran "leer", reflexionar, contextualizar e interpretar los hechos sociales, que como bien apuntan Augé y Colleyn (2005: 12), no son identificados como objetos estables, sino como conjuntos de procesos que no cesan de evolucionar bajo la acción del ser humano. Es decir, se debe crear un espacio de pensamiento, en el horizonte de la hermenéutica contemporánea.

El marco epistemológico y teórico con el que se ha sustentado este trabajo, problematizando el objeto de estudio, es la tetrádica perspectiva de análisis: la complejidad y la subjetividad en el doble entramado de la sociedad postmoderna y de la formación social mexicana. Por la limitación del espacio participativo, en este artículo solamente se bosquejará dicho tetraedro paradigmático.

No es posible abordar algún fenómeno social desconociendo la configuración postmoderna como lógica cultural del capitalismo tardío. Sus teóricos hablan de las dimensiones cultural, socioeconómica y geopolítica de la postmodernidad y de la hipermodernidad, que ya se está gestando. El planteamiento básico de esta investigación considera cómo la actual modificación profunda del tejido social se manifiesta, entre otras formas, a través de la proliferación de fenómenos de resacralización, que paradójicamente atraviesan y permean la sociedad del conocimiento. Lipovetsky y Sebastién (2006: 97) abordan el despertar de las espiritualidades y las nuevas demandas de identidad en la hipermodernidad -superación de la etapa presentista de la postmodernidad- en la que se dan los renacimientos religiosos, las resurrecciones étnicas, se vigorizan los sistemas de referencia que remiten al pasado y se refuerzan las preocupaciones por tener raíces y memoria. En México, uno de esos revivals étnico-religiosos es el culto a la Santa Muerte, que está reconfigurando una subjetividad emergente entre sus adoradores.

Así mismo, la perspectiva de la subjetividad es la mirada y el ancla que permite entender las diferentes mediaciones culturales, socioeconómicas y geopolíticas de la postmodernidad, resultado y al mismo tiempo estructurantes de ese mismo tipo de sociedad de la cual proceden.

Se considera que la matriz epistemológica y teórica de esta concepción de la emergencia de las subjetividades, de la indeterminación y determinabilidad de los sujetos sociales históricos, es precisamente el pensamiento complejo. Se le ha llamado ciencia postmoderna a la complejidad. Algo hay de ello: la conciencia de la fragilidad del pensamiento, el no teleologismo, el rechazo de los grandes sistemas racionales y de las macro narrativas, así como el surgimiento de una conciencia ecológica son aspectos epocales que crean las condiciones de apertura para aceptar una propuesta de ciencia menos dogmática, más crítica, más dialógica y multicultural.

Además, no es posible reducir la densidad cultural actual a la configuración postmoderna occidental. La postura 
epistemológica compleja asume que hay varias lógicas, y que por lo tanto hay diferentes formas de acercarse a los escenarios heterogéneos de la realidad. Por lo tanto, se plantea que no es suficiente asumir solamente la postmodernidad como referente teórico-contextual del estudio. En México no hay una formación social única, no hay una sociedad homogénea y monolítica. Por ello, al lado de Bauman se recurre a pensadores como Guillermo Bonfil Batalla (1999), analista de la sociedad pluriétnica y multicultural del México contemporáneo, para entrar en una vertiente, en una relectura de la realidad que no se restrinja al horizonte postmoderno. También debe remitirse aquí a Hugo Zemelman, quien magistralmente esboza el perfil de la indeterminación y la determinabilidad de los sujetos sociales de América Latina:

(...) todas las posibilidades de sujeto concebidas están presentes y potencialmente vivas: son y somos occidentales, indios, mestizos, desindianizados, híbridos, modernos, posmodernos y arcaicos; (...) urbanitas rurales y campesinos cosmopolitas; subordinados, resistentes y protagónicos; guiados por utopías y prácticas contingentes; definidos por identidades sociales y culturales que se ponen en suspenso en el mismo momento de ejercerlas, para contradecirlas; con creencias en mitos $\mathrm{y}$ congregados en ceremoniales y ritos, siendo a la vez seculares; perteneciendo a un nuevo mundo de memoria milenaria (1997: 12).

La simiente del pensamiento complejo con su horizonte gnoseológico de historicidad de lo social, de no-linealidad, de contextualización, de interdisciplinariedad ha encontrado un terreno fértil en América Latina y se constituye como el marco epistemológico y teórico desde el cual se está reformulando el problema de la subjetividad, es decir, de la emergencia y constitución de los sujetos sociales y la comprensión de la concepción que del mundo social construyen sus actores. Es este un horizonte de estudio de la realidad social que gira alrededor de los actores, de sus modos de vida cotidiana y sus formas de interpretar la realidad en contextos témpora-espaciales determinados, ya que el espacio, el movimiento y el tiempo son la forma de existencia del hombre histórico (Lara y Morín: 2006).
Se está ante dos propuestas con congruencia interna mutua, en diálogo y vinculación recursiva, que tratan de aprehender la realidad social desde la interrelación entre sistemas y actores: por un lado desde la complejidad y por el otro a través de la construcción de la categoría de las subjetividades colectivas (la heterogeneidad de los sujetos sociales como manifestación de su historicidad); "desde la articulación de lo objetivo (sistemas, estructuras, instituciones) con lo intersubjetivo (representaciones, identidades, vida cotidiana)" (Rodríguez Salazar, 1996: 200).

Dos de los representantes más destacados sobre la subjetividad son Berger y Luckmann (2001). Ellos apuntan a los universos simbólicos como categorías matriciales de significación, los cuales legitiman sentidos, justifican las interpretaciones que a través de la internalización un grupo otorga a la realidad circundante $\mathrm{y}$, por lo tanto, aseguran el orden, la coherencia y el sentido a las biografías individuales, resolviendo el caos o la frágil significación institucionalizada del mundo (Carretero Pasín, 2001: 2). Para Berger y Luckmann, los universos simbólicos son "cuerpos de tradición teórica que integran zonas de significado diferentes y abarcan el orden institucional en una totalidad simbólica" (2001: 124). Se puede hablar entonces de "la matriz de todos los significados objetivados social y subjetivamente reales; toda la sociedad histórica y la biografía de un individuo se ven como hechos que ocurren dentro de ese universo" (2001: 35).

Para el objeto de estudio abordado en este artículo, esta categoría tiene gran valor heurístico y metodológico, ya que la integración en un universo simbólico permite el análisis y la interpretación integral de las vivencias cotidianas, pero también de las situaciones marginales, de las biografías precarias (Reguillo, 2009), del fenómeno de la muerte y del culto a la Santa Muerte.

\section{Metodología de abordaje}

La tetrádica perspectiva de análisis: la subjetividad, su articulación con el pensamiento complejo y con el paradigma de la postmodernidad, y la coexistencia del mosaico multicultural mexicano, ha permitido encontrar un ángulo desde el cual pensar la realidad social y en particular el fenómeno socio-cultural-comunicativo del culto a 
la Santa Muerte, ya que las creencias religiosas se encuentran asociadas a la forma en que un grupo social percibe y construye la realidad en un juego dialógico con el entorno, que se convierte en estructurador, al tiempo que es estructurado. Se tiene un horizonte epistemológico y teórico interdisciplinario con el cual intentar el entendimiento de las dinámicas internas/externas de la gestación y configuración de esa creencia, la dialéctica interna en que descansa la constitución de la subjetividad de las comunidades de fieles.

Por lo tanto, se delínean dos grandes horizontes de producción de significación en torno a la representación social de la muerte y su "canonización": el histórico y el fenomenológico; y ante la imposibilidad de abordarlos por extenso en este documento, se exponen sólo sus principales dimensiones:

\subsection{Horizonte histórico: la construcción en el tiempo de la representación social de la muerte y su deificación}

Se trata de encarar la concepción de la muerte, su sentido, el enucleamiento de la sociedad prehispánica en torno a su culto, pasando luego a la Conquista y la Colonia como espacios reconfiguradores de una nueva subjetividad social en la combinatoria cultural, para navegar posteriormente en el marco referencial actual que ha sido llamado el de la confluencia entre el México profundo y la sociedad del riesgo. Un recorrido orientado por la perspectiva teórica asumida que permite incursionar en los escenarios histórico-culturales con sus flujos cambiantes y reconfiguradores de nuevos sujetos, que constituyen el marco referencial de la concepción de la muerte, su deificación y nuevas apropiaciones sociales de sentido.

\subsubsection{La muerte y su deificación en el mundo prehispánico}

En el mundo prehispánico la muerte ocupó un lugar preponderante al ser considerada como punto final y de partida, como lugar para la generación y regeneración. La muerte estaba integrada plenamente en la vida del universo prehispánico. Las deidades y las fiestas de la muerte con su fuerte carga simbólica demuestran el profundo arraigo existencial de la muerte en la vida de las culturas prehispánicas (Johansson, 2003: 4).
No recordamos ningún otro pueblo -afirma Eduardo Matos Moctezuma- que haya representado la muerte en forma tan obsesiva como algunas de nuestras culturas prehispánicas. ¿Culto a la muerte? Más bien culto a la vida.. . A través de la muerte (1971: 6).

Cuando los cronistas españoles comenzaron a elaborar textos sobre lo que ocurría en los pueblos nativos, existió una confusión respecto a la muerte: los españoles creían que tantas manifestaciones en torno a la muerte reflejaban sentimientos de miedo, de terror, tal y como se daba en su cultura cristiano-europea-española del siglo XVI: la muerte y el juicio con su disyuntiva eterna del paraíso o el infierno. Dicha percepción era errónea y resultado del eurocentrismo imperante en los conquistadores y su cerrazón frente a las diferencias culturales. De hecho, estas expresiones tenían meramente una función catártica para quienes se quedaban en el mundo terrenal. Para Johansson, mostraban el profundo arraigo existencial de la muerte en la vida de las culturas prehispánicas (2003).

Las deidades de la muerte en el México antiguo forman parte precisamente de una concepción cosmogónica y teleológica en la que se entremezclan diferentes mitos sobre los dioses, la creación del hombre y las diferentes regiones a donde iban los muertos: el sol, el Tlalocan y el Mictlán. Se trata de una conceptualización religiosa que se articula con una concepción, por así llamarla, arquitectónica y unitaria entre la tierra, los movimientos de los astros, el devenir de la vida, de las estaciones, de los ciclos. Por ser un pueblo agrícola se tenía conciencia del ciclo de la naturaleza: el tiempo de lluvia en que las plantas reverdecen, crecen y dan frutos; el tiempo de sequías en el que no llueve y todo es muerte.

Estamos frente a una conjunción de observaciones y saberes científicos plasmados en calendarios y edificios, y de creencias míticas que otorgan sentido acabado a los fenómenos cuando el conocimiento se muestra insuficiente, pero que juntos forman el andamiaje de una cultura, de una forma de vida colectiva

Sus deidades eran Mictlantecuhtli, Señor de los muertos, quien también era invocado cuando los espíritus trataban de regresar al mundo, y Mictlancíhuatl, ambos Señores del inframundo y moradores del Mictlan, "tierra de los muertos"; 
Tlaltecuhtli era la diosa de la tierra, devoradora de cadáveres y encargada de parirlos a su destino final.

El calendario es una muestra de la importancia de Mictlantecuhtli en la vida cotidiana en el mundo mexica. Durante el calendario de 365 días, se hace presente en la fiesta doble integrada por las veintenas de Miccailhuitontli y Huey Miccaílhuitl. En el calendario de 260 días, Mictlantecuhtli aparece a la vez como Sexto Señor del Día, Quinto Señor de la Noche, patrón del día Itzcuintli, de la trecena que inicia el 1 Técpatl y su imagen es el signo del día Miquiztli.

En el códice Borgia, Mictlantecuhtli y Quetzalcóatl son representados como principios opuestos y complementarios, como la muerte y la exhalación de vida que forman el ciclo básico del universo. A pesar de que Mictlantecuhtli era el dios de la muerte, también estaba profundamente asociado a la vida: en el inframundo se resguardaban las semillas de la vida que en sí mismas eran los antepasados difuntos. Se han encontrado representaciones que tratan desde el momento de la fecundación, el embarazo y el parto y en estas siempre se encuentra la imagen de Mictlantecuhtli.

\subsubsection{La representación de la muerte en la Colonia}

Europa ha conformado, a través de una larga tradición cultural, un código de significación o sistema de signos desde la visión epistemológica de la iglesia católica. Uno de los resultados de este proceso semiótico es la simbología escatológica cristiana, o simbología de la muerte, manifestada a través del lenguaje artístico, en el que se conjuntaban aquellos elementos que servían para adoctrinar o ilustrar didácticamente pasajes de la Escritura y verdades de fe, o bien, para incitar a los fieles a vivir de acuerdo a la moral cristiana.

El eje referencial de la iconografía escatológica ortodoxa-normatizada es la consideración de la finitud de la vida, de la entrada de la muerte en el mundo por la culpa original del viejo Adán, y del triunfo de Cristo, nuevo Adán, que vence a la muerte y al pecado.

Como ilustra Elsa Malvado, fue a través de la pintura, de la escultura, de la música, del teatro, que se buscó siempre representar ante los creyentes la mortalidad de la humanidad, la transitoriedad de la vida terrenal y la esperanza en una vida futura de plenitud perenne o de condenación eterna. En el testamento de Felipe II se lee: "No hay cosa más cierta que la muerte. Ni más incierta que la hora de ella". Esta frase compendia el ánimo de los católicos, que esperaban tener una "buena muerte" y para ello vivían preparados. Incluso formaron cofradías de La Buena Muerte, asociaciones que asistían a sus miembros para que pudieran recibir los sacramentos a la hora del tránsito final, y que, además, les garantizaban post mortem las oraciones de todos los cofrades para la salvación de su alma.

Este universo simbólico es el que se predica y se transmite entre los indígenas de la Nueva España como parte de los procesos de occidentalización. Se integra en la propuesta de un nuevo esquema de interpretación de la realidad, muy diferente de la concepción de las deidades de la muerte del universo mesoamericano. "El México antiguo no conocía ningún Juicio Final, ni infierno alguno que hiciera temblar a los hombres. Faltando los supuestos, es natural que no hubiera algo como una danza macabra precortesiana" (Westheim, 1983: 76).

\subsection{Horizonte fenomenológico: el culto a la Santa Muerte y las dinámicas internas y externas de su configuración simbólica}

Toca ahora abordar el fenómeno de la devoción a la Santa Muerte y su desarrollo; tratar de entender las dinámicas internas/externas de la gestación y configuración de esa creencia, configuradora de una estructura identitaria cultural y religiosa.

En este punto, es necesario dejar en claro que la postura de los autores no es en ningún momento ni apologética del movimiento, ni tampoco inquisitorial; este estudio no pretende calificar o descalificar, desde una ideología y normativa preestablecidas. Lo que se busca es entender las innovaciones de sentido que colectivamente va construyendo la comunidad cultual; en este caso, la dialéctica interna en que descansa la constitución de una subjetividad emergente de las comunidades de los fieles de la Santa Muerte.

Se intenta reunir y organizar el conjunto de manifestaciones (prácticas rituales) que realizan los seguidores de la Santa Muerte y descubrir las dimensiones culturales y simbólicas que subyacen en ellas; estudiar las interrelaciones comunicativas que se crean entre las comunidades de fieles al compartir el mismo objeto de culto y veneración. La consecuente exploración incluyó: 
- El trabajo etnográfico en mercados, vecindades, templos, altares domésticos y un bar dedicado a "la Santa”. Todo esto en la ciudad de San Luis Potosí y en algunos lugares del Altiplano Potosino y de la región Media del mismo estado, así como también, aunque en menor medida, en la Ciudad de México, Culiacán, Sinaloa; y Nuevo Laredo, Tamaulipas

- La observación participante en peregrinaciones hacia santuarios de la Santa Muerte y en la celebración de sus liturgias.

- El manejo de entrevistas en profundidad e historias de vida con informantes clave, como son las y los guardianes del culto

- El análisis del discurso de libros y revistas devocionales, diseminadores del culto a la Santa Muerte

- La interpretación de la iconografía escatológica de la efigie de la Santa Muerte desde la semiótica de la cultura.

A continuación se reseñan someramente y se interpretan algunos hallazgos relevantes:

\subsubsection{La resignificación de la efigie de la Santa Muerte}

El fenómeno reciente del culto a la Santa Muerte en México es una expresión religiosa sincrética y heterodoxa, en la que perviven elementos de la tradición indígena fuertemente permeados por una lectura ambigua de la fe cristiana y una dación de sentido reidificante al ícono de La Santísima.

Es fácil constatar que iconográficamente hay semejanza entre los objetos artísticos y religiosos prehispánicos referidos a la muerte y el arte cristiano colonial. Sin embargo, su matriz de significación es totalmente distinta. Para el cristianismo, la imagen de la muerte es solamente la representación de la mortalidad del hombre, no existe in re o per se, y por lo tanto, no puede ni debe ser sacralizada, y su veneración o adoración constituye una idolatría.

Pero no es de extrañar que a veces los indígenas interpretaran esos símbolos de acuerdo con sus antiguos marcos de referencia, con sus imaginarios y representaciones sociales que se negaban a desaparecer e hicieran un collage de lo viejo y lo nuevo, transformando erróneamente esos símbolos y relatos cristiano-occidentales en una personalización de la muerte, en un objeto de culto y veneración. Son escasos los vestigios documentales que den fe de esas prácticas híbridas de religiosidad popular que articulan referentes cristianos con rasgos de chamanería, hechicería y adivinación, rastros de prácticas muy arraigadas en la sociedad teocrática mexica. Sin embargo, a través de historias de familia se ha corroborado que aún en el México independiente se dieron esas lecturas aberrantes o ambiguas del cristianismo, postura que subyace en los seguidores de la Santa Muerte.

\subsubsection{El símbolo: transfiguración y manifestación de lo divino}

El símbolo es un signo que "se caracteriza fundamentalmente por la imposibilidad para el pensamiento directo de captar su significado de una manera exterior al proceso simbólico mismo" (Garagalza, 1990: 50). La simbolización es parte del proceso de semiosis por el cual, el que interpreta, liga la imagen sensible con un sentido, revistiéndola con un excedente de significación. Es así como lo sensible es conducido a su sentido profundo: se transfigura.

El símbolo es lo inefable, "aquello para lo cual no existe ningún concepto verbal, se manifiesta, se encarna, en y por la imagen, se expresa en una figura. El símbolo es la epifanía de un misterio" (Durand, citado en Garagalza, 1990: 51). Por lo tanto, la interpretación del símbolo no se rige por un patrón racional, ya que, apunta el mismo Garagalza: "Es el alma del hermeneuta el lugar de manifestación de esta realidad simbólica que, en cuanto tal, no es meramente objetiva por cuanto que no es independiente ni existe separadamente del yo que la medita".

Aplicando esta visión al análisis del signo de la Santa Muerte, se puede decir que el proceso de simbolización o el otorgamiento de ese significado inefable e invisible a la imagen de la Santa Muerte, se da cuando el representamen es dotado de connotaciones que lo sobrepasan, en concordancia con las representaciones sociales del sujeto colectivo y con la evolución o revolución y quiebre respecto de algunas representaciones sociales normatizadas.

La claridad y la distinción no son características del símbolo: este no puede ser explicado de una vez por todas, ni tiene un sentido unívoco, sino que está inmerso en la ambigüedad y en la oscuridad. Las maneras de avanzar para crear cierta coherencia entre la imagen y el sentido son "las redundancias míticas, rituales, iconográficas" (Durand, 86: 18). Por eso la creencia en la Santa Muerte es alimentada 
con una ritualidad ecléctica y rebosante de objetos, de nuevas prácticas, inventadas por los promotores del culto, con la referencia constante a las marcas indiciales de los favores recibidos, con capillas y altares donde vuelve a imperar el horror vacui del barroco y del rococó, abigarramiento que genera una atmósfera agobiante.

Los fieles van así construyendo la simbolización de la Santa Muerte a través de las prácticas de veneración y adoración privadas y públicas, como son: las advocaciones con las que se refieren a ella, tales como la Santísima, la Niña Blanca, la Gran Señora, la Flaquita; la vestimenta que la envuelve, semejante a la de las imágenes marianas; los actos solemnes de ceremonias de coronación de sus efigies que son veneradas públicamente; el cetro que se coloca en sus manos, la balanza, la guadaña; todos son índices que hablan del reconocimiento del sentido simbólico que tiene entre sus fieles.

\section{Reflexiones y aportaciones en torno al objeto de estudio}

A medida que se avanzó en la presentación de este estudio, fue posible realizar una cierta reconstrucción conceptual de los hallazgos. Para finalizar, se trata de articular los postulados teórico-epistemológicos con los descubrimientos verificables que la inmersión en los horizontes histórico y fenomenológico fueron mostrando, de relacionarlos e interrelacionarlos, de encontrar sus mutuas dependencias para descubrir las dimensiones cultural y simbólica del fenómeno, el universo de significación que la comunidad cultual atribuye a la realidad y que constituye su propia subjetividad.

\subsection{El culto a la Santa Muerte y el imaginario mágico-religioso del miedo}

La devoción a la Santa Muerte es un movimiento constituyente y constitutivo de la sociedad del riesgo. Sus adeptos miran hacia la muerte, personificada, como la única certeza personal y grupal a la que le confían la vida. Paradójicamente la muerte se convierte en dadora de sentido de la vida.

Los miedos, dice Rossana Reguillo (2000 y 2006) son individualmente experimentados, socialmente construidos $\mathrm{y}$ culturalmente compartidos, es decir, son constitutivos de la subjetividad individual, modelan la subjetividad colectiva y se integran al tejido simbólico social. En el culto a la Santa Muerte estos tres elementos se entrelazan y condicionan mutuamente para construir la sociabilidad del miedo. Se ha afirmado que el miedo a la muerte es el fantasma omnipresente en la sociedad del riesgo. Berger y Luckmann (2001: 131) plantean que en cualquier orden institucional es necesario integrar el fenómeno de la muerte en un universo simbólico para legitimarla, es decir, para que los individuos de una comunidad puedan seguir viviendo en sociedad después de la muerte de otros y para que, anticipando la propia muerte, con un terror mitigado, puedan seguir su vida cotidiana. Difícil tarea, que sólo se puede lograr integrando el fenómeno de la muerte dentro de un universo simbólico.

Para los seguidores de la Santa Muerte, el miedo omnipresente y líquido adquiere un rostro y un nombre: la muerte misma, la propia muerte; pero la auto referencia es desbordada por el referente religioso ancestral que está en el sedimento de la memoria colectiva. Entonces ponen en juego una estrategia para aliviar la conciencia tan clara y cercana de la propia mortalidad (mors certa, hora incerta): la estrategia heterónoma religiosa de la reificación o personalización y sacralización de la muerte, que paradójicamente protege de la misma.

Es así como la cultualización de la muerte viene a otorgarle a la misma una dimensión simbólica, que trasciende el mundo de la experiencia cotidiana, el mundo de la vida. Esto se evidencia a los ojos de los devotos con la creación de un ícono, que remite a un imaginario que lo trasciende y lo dota de sentido. Así reificada la muerte, se mitiga el terror ante el misterio, se puede seguir viviendo, y llega a convertirse, paradójicamente, en un símbolo sagrado de certeza y de esperanza.

\subsection{El diálogo recursivo entre dos universos de significación}

Los cauces de la semiosis se encuentran ligados a los procesos de subjetivación social. En el caso de la Santa Muerte es una comunidad de creyentes la que resignifica el fenómeno de la creencia religiosa hegemónica en México -la cristiana- y la orienta hacia un tipo de cultualidad que implica un rechazo parcial de los núcleos invariables de sentido tradicionales y la apertura a nuevos horizontes de sentido. 
El flujo de la semiosis y la nueva condensación de sentido se ancla en el catolicismo popular, retoma el universo indígena $y$, en tiempos de crisis, violenta, descerraja la doxa establecida y construye una nueva propuesta cultural: la canonización de la muerte. La alquimia hermenéutica nos entrega así un símbolo o signo acabado de la tensión entre la finitud humana y la dación de vida, la Santa Muerte. Como en el universo prehispánico, hoy se reencuentran los principios antagónicos de muerte y vida.

Desde la perspectiva moriniana de la complejidad, el culto a la Santa Muerte puede verse como un ejemplo de bucle dialógico: es un vestigio, un reducto de una sociedad sacralizada como la prehispánica, que se resiste a morir, y que entabla un diálogo recursivo con otro universo de significación también sacralizado y teleológico, el cristiano occidental, el cual le propone un nuevo esquema de interpretación de la realidad. El bucle dinámico sigue creciendo, en la integración de causas endógenas y exógenas, y hoy se orienta en una determinada dirección: desentierra a la muerte, con un nuevo rostro, con una fuerza personalizada e individualizada, como símbolo supremo que invita a sus seguidores a entrar en el universo fascinante del misterio y de la noche.

\section{Referencias}

Ariès, P. (2008). Morir en Occidente desde la Edad Media hasta nuestros días. Córdoba, Argentina: Adriana Hidalgo Editora.

Augé, M., y Colleyn J.P. (2005) Qué es la antropología. Barcelona, España: Paidós.

Bauman, Z. (2003). Comunidad. En busca de seguridad en un mundo hostil. Madrid, España: Siglo XXI.

Bauman, Z. (2008). Tiempos líquidos. Vivir en una época de incertidumbre. Cd. de México, México: Consejo Nacional para la Cultura y las Artes y Tusquets Editores.

Berger, L., y Luckmann T. (1997). Modernidad, pluralismo y crisis de sentido. La orientación del hombre moderno. Barcelona, España: Paidós.

Berger, L., y Luckmann T. (2001). La construcción social de la realidad. Buenos Aires, Argentina: Amorrortu Editores.

Bonfil Batalla, G. (1987). México profundo. Una civilización negada. Cd. de México, México: Random House Mondadori.

Carretero Pasín, Á.E. (2001). "El poder de los imaginarios sociales: una reflexión filosófico-sociológica en torno a la legitimación de la dominación en las sociedades posmodernas". AllBusiness.com, enero. 1-10. Disponible en: http://www.allbusiness.com/sector-61-educationalservices

Durand, G. (1986). La imaginación simbólica. Buenos Aires, Argentina: Amorrortu.

Garagalza, L. (1990). La interpretación de los símbolos. Hermenéutica y lenguaje en la filosofía actual. Barcelona, España: Ánthropos.

Garagalza, L. (2002), Introducción a la hermenéutica contemporánea. Barcelona, España: Ánthropos.

Johansson, K. P. (2003). "La muerte en Mesoamérica". Arqueología Mexicana, marzo-abril, n. 60. Cd. de México, México: Editorial Raíces. 46-53

Lara Mireles, M.C., y Morín, D. (2006). "Espacio, tiempo y discursividad", XIII Anuario de la Comunicación CONEICC, Cd. de México, México: CONEICC, 105-122.

Lara Mireles, M.C. (2009). "El culto a la Santa Muerte y el redibujamiento de una identidad colectiva diferenciada". Memoria del XIII Encuentro Latinoamericano de Facultades de Comunicación Social. La Habana, 19-22 de octubre de 2009. Disponible en: www.felafacs.org/l ahabana

Lara Mireles, M. C., Ortiz S., y Torres M. (2010). "De Mictlantecuhtli a la Santa Muerte. Prácticas culturales y comunicativas en torno a la figura de la muerte desde la sociedad mexica hasta la sociedad del riesgo", Memorias del XXII Encuentro Nacional AMIC, 2010. Versión electrónica. Cd. de México, México: AMIC

Lipovetzky, G., y Sebastién, Ch. (2006). Los tiempos hipermodernos, Barcelona, España: Anagrama.

Matos Moctezuma, E. (1971). "La muerte en el mundo prehispánico". En Miccaihuitl. El Culto a la Muerte. Artes de México, n. 175. Cd. de México, México: Artes de México. 6-36.

Morin, E. (2004). "La epistemología de la complejidad". Gazeta de Antropología 20. Consultada en http://hdl.ha ndle.net/10481/7253. El texto corresponde a las páginas 43-77 de L'intelligence de la complexité, editado por L'Harmattan, París, Francia: 1999. Traducción de José Luis Solana Ruiz.

Morin, E. (2007). Introducción al pensamiento complejo. Barcelona, España: Gedisa editorial.

Reguillo, R. (2000). "Ciudad y comunicación. La investigación posible". En Orozco, G. (coordinador)Lo viejo y lo nuevo. Investigar la comunicación en el siglo XXI. Madrid, España: Ediciones de la Torre, 33-49.

Reguillo, R. (2009). "México: contra el ábaco de lo básico. Agendas de país y desafíos para la comunicación". En Martín Barbero, J. (Coordinador). Entre saberes desechables y saberes indispensables. (Agendas de país desde la comunicación). Bogotá, Colombia: Friedrich Ebert Stiftung. 37-49 
Rodríguez Salazar, T. (1996). "El itinerario del concepto de mundo de la vida. De la fenomenología a la teoría de la acción comunicativa". Comunicación y sociedad, Universidad de Guadalajara, n. 27 (1996, mayo-agosto), 199-214.

Westheim, Paul. (1983). La calavera. Cd. de México, México: Fondo de Cultura Económica.

Zemelman, H. (1997). "Presentación”, en León, Emma y Zemelman, Hugo, Subjetividad: Umbrales del pensamiento social, Barcelona, España: Ánthropos y Ciudad de México, México: UNAM, 9-18.

Zemelman, H. (1997), "Sujetos y subjetividad en la construcción metodológica", en León, Emma y Zemelman, Hugo, Subjetividad: Umbrales del pensamiento social, Barcelona, España: Anthropos y Cd. de México, México: UNAM, 21-35. 